\title{
New Bismuth Germanate Oxide Nanoparticle Material for Biolabel Applications in Medicine
}

\author{
M. J. Oviedo, ${ }^{1}$ O. E. Contreras, ${ }^{1}$ Y. Rosenstein, ${ }^{2}$ R. Vazquez-Duhalt, ${ }^{1}$ Z. S. Macedo, ${ }^{3}$ \\ G. G. Carbajal-Arizaga, ${ }^{4}$ and G. A. Hirata ${ }^{1}$ \\ ${ }^{1}$ Universidad Nacional Autónoma de México, Centro de Nanociencias y Nanotecnología, Km 107 Carretera Ensenada-Tijuana, \\ 22800 Ensenada, BCN, Mexico \\ ${ }^{2}$ Instituto de Biotecnología, UNAM, Avenida Universidad 2001, 62250 Cuernavaca, MOR, Mexico \\ ${ }^{3}$ Departamento de Física, Universidade Federal de Sergipe, 49100-000 Sao Cristóvão, SE, Brazil \\ ${ }^{4}$ Departamento de Química, Universidad de Guadalajara, Marcelino García Barragán 1421, 44430 Guadalajara, JAL, Mexico
}

Correspondence should be addressed to M. J. Oviedo; moviedo@cnyn.unam.mx

Received 11 September 2015; Revised 10 December 2015; Accepted 31 December 2015

Academic Editor: Ilaria Armentano

Copyright (C) 2016 M. J. Oviedo et al. This is an open access article distributed under the Creative Commons Attribution License, which permits unrestricted use, distribution, and reproduction in any medium, provided the original work is properly cited.

Bismuth germanate $\left(\mathrm{Bi}_{4} \mathrm{Ge}_{3} \mathrm{O}_{12}, \mathrm{BGO}\right)$ has been the focus of several studies due to its scintillation properties. It has been employed as detector in scientific research and medicine, and herein we studied its possible biomedical applications. The photoluminescence properties of the uncoated and protein-coated nanoparticles were analyzed in different body fluids, at different $\mathrm{pH}$. The nanoparticles yielded blueish-white luminescence with a maximum emission peak at $485 \mathrm{~nm}$ corresponding to the ${ }^{3} \mathrm{P}_{1} \rightarrow{ }^{1} \mathrm{~S}_{0}$ electron transition of $\mathrm{Bi}^{3+}$. They showed luminescence properties at different $\mathrm{pH}$ values and in human fluids, such as urine and blood serum. Finally, the BGO nanoparticles were functionalized with the anti-HLA I W6/32 monoclonal antibody and the capacity of the antibody-loaded nanoparticles to recognize the cognate antigen (HLA I) of the W6/32 mAb was assessed on the human promyelocytic leukemia cell line THP-1. The possibility of functionalizing BGO nanoparticles with W6/32 antibodies and their specificity to identify THP-1 cells make them promising candidates for biomedical applications as biolabels.

\section{Introduction}

Materials science and engineering are capable of tuning the physicochemical properties of materials to transform technologies in many areas including chemical manufacturing, food industry, medicine, personal care, electronics, sensors, and catalysis [1-7]. Surface modifications of nanoparticles will provide new opportunities for their effective application in a wide variety of fields, such as the peptide and protein surface modifications recently applied in nanomedicine $[8$, 9]. In the rapidly emerging field of nanobiotechnology, new kinds of materials that combine the properties of biological molecules with nanostructured materials, such as recognition, catalysis, or other properties, combined with those of nanomaterials offer a wide range of novel possibilities to the medical industry. Inorganic nanoparticles with luminescent properties have been used as biolabels, for example, quantum dots (QDs) for in vivo imaging. QDs possess bright emission and are capable of identifying specific cells when functionalized with antibodies [10]. However, the emission wavelength strongly depends on the particle size, and the present QD synthesis methods must still control particle size [11]. Nanocrystalline silicon has also been used as a biolabel and because it shows biocompatibility, it was tested inside a biological tissue. However, once inside, its luminescence properties decreased considerably [12]. The luminescent activation of a biolabel can provide signs that enable earlier diagnosis by, for example, discerning the presence of certain compounds at a primitive stage of the disease.

In materials science, bismuth germanate $\left(\mathrm{Bi}_{4} \mathrm{Ge}_{3} \mathrm{O}_{12}\right.$, $\mathrm{BGO}$ ) has received much attention for its scintillation properties. A scintillator is a luminescent material that converts ionizing (high-energy incident) radiation into light with very short decay time ( $\ll \mu \mathrm{s})$. The main application of BGO single crystal scintillators has been in the medical imaging field as detector in positron emission tomography (PET) equipment 
[13], but so far, it has not been examined as a biomaterial and/or biolabel. The aim of this work was to investigate the synthesis and optical properties of bismuth germanate and to explore its possible use as synthetic biolabel. The interaction of BGO with body fluids such as human urine, blood serum, and protein was explored. Finally, the BGO nanoparticles were functionalized with W6/32 antibodies and tested to detect human cancer cells (THP-1 cell line).

\section{Experimental Procedures}

2.1. BGO Nanoparticles Synthesis. A mixture was prepared containing $4.049 \mathrm{~g}$ of high purity $\mathrm{Bi}_{2} \mathrm{O}_{3} \cdot \mathrm{XH}_{2} \mathrm{O}$ (Puratronic 99.999\%) and $0.631 \mathrm{~g}$ of $\mathrm{GeO}_{2}$ (Alfa Aesar 99.98\%) according to stoichiometric calculations and dispersed in a solution of $4 \% \mathrm{HNO}_{3}(40 \mathrm{~mL})$. In another flask, $2.58 \mathrm{~g}$ of L-tartaric acid (Aldrich, USA) was dissolved in $10 \mathrm{~mL}$ of deionized water and the individual solutions were mixed under constant stirring. These two solutions were then mixed and stirred for $24 \mathrm{~h}$ at room temperature; the resulting solution was maintained at $\mathrm{pH}$ 1. Thereafter, the mixture was heated under constant stirring to $80^{\circ} \mathrm{C}$ and kept at this temperature for $2 \mathrm{~h}$, which made it denser, eventually forming the sol. Subsequently, the sol was heated to $120^{\circ} \mathrm{C}$ producing a gel which was dried to form the precursor. The as-synthesized powders were heated twice in air, the first starting gradually from room temperature to $950^{\circ} \mathrm{C}$ at a rate of $1^{\circ} \mathrm{Cmin}^{-1}$. The powders were maintained at this temperature for $4 \mathrm{~h}$ and then cooled down at the same rate. The second annealing was performed keeping the powders at $800^{\circ} \mathrm{C}$ for $1 \mathrm{~h}$.

\subsection{BGO Nanoparticle Characterization. X-ray diffraction} (XRD) analysis was performed with a Philips X'pert diffractometer equipped with $\mathrm{CuK}_{\alpha}$ radiation $(\lambda=0.15406 \mathrm{~nm})$. Measurements in a $2 \theta=20-60^{\circ}$ range were taken with a step size of $0.1^{\circ}$ and a $1 \mathrm{sec}$ dwell per point. Transmission electron microscopy (TEM) images were obtained with a JEOL-2010 operated at $200 \mathrm{kV}$ accelerating voltage. Atomic force microscopy (AFM) images were obtained with a XEBIO of Park Systems. The photoluminescence (PL) properties of the powders were studied with a fluorescence spectrophotometer (Hitachi FL-7000). A Nicolet 6700 spectrometer with an attenuated total reflectance device was used to obtain infrared spectra with a resolution of $2 \mathrm{~cm}^{-1}$ and accumulation of 32 scans. BGO powders were characterized by Raman spectroscopy using a Jobin Yvon Horiba LabRam-HR system interfaced with an Olympus BX41 optical microscopy and an Ar laser (Olympus TH4-100, $20 \mathrm{~mW}$ at $532 \mathrm{~nm}$ ) source. The scintillator properties were studied by radioluminescence (RL) measurements obtained by the D08B:XAFS2 beam line at the Brazilian Synchrotron Light Laboratory (LNLS) in Campinas/SP, Brazil, with the X-ray beam tuned at $7 \mathrm{keV}$. The RL signal was obtained using a spectrometer (Ocean Optics HR2000). All optical measurements were performed at room temperature.

2.3. BGO Nanoparticle Functionalization. The BGO functionalization method was standardized as follows: $50 \mathrm{mg}$ of
BGO nanoparticles was mixed with $50 \mu \mathrm{L}$ of bovine serum albumin (BSA) $(8 \mathrm{mg} / \mathrm{mL})$ and $10 \mu \mathrm{L}$ of $0.1 \mathrm{M}$ 1-ethyl-3-(3dimethylaminopropyl) carbodiimide (EDC). The mixtures were completed up to $1 \mathrm{~mL}$ with $10 \mathrm{mM}$ Tris- $\mathrm{HCl}$ buffer $(\mathrm{pH}$ 5.5) to maintain the protein stable and active. The suspensions were incubated at $37^{\circ} \mathrm{C}$ for $2 \mathrm{~h}$ and then centrifuged at $6,000 \mathrm{rpm}$ for $4 \mathrm{~min}$ at $4^{\circ} \mathrm{C}$. The suspensions of conjugated nanoparticles were washed two times with Tris- $\mathrm{HCl}$ buffer and then three times with distilled water, and the supernatant was recovered by centrifugation. Two controls were included, one with uncoated nanoparticles (BGO-EDC) to estimate the possible unspecific adsorption of reagent dye, and another with BGO nanoparticles and BSA protein without EDC as linker (BGO-BSA) to determine if the nanoparticles can be coated with BSA without linker.

2.4. Conjugated Protein Determination. To corroborate the protein functionalization of $\mathrm{BGO}$, the attached protein was quantified. For protein quantification, $50 \mathrm{mg}$ of coated and $50 \mathrm{mg}$ of uncoated nanoparticles were suspended in $900 \mu \mathrm{L}$ of distilled water and $100 \mu \mathrm{L}$ of Bio-Rad reagent was added in a $1.5 \mathrm{~mL}$ Eppendorf tube. This amount of reagent dye was calculated to produce 0.5 absorbance $(\lambda=595 \mathrm{~nm})$ units with an excess of protein. After $15 \mathrm{~min}$ incubation, all suspensions were centrifuged at $6,000 \mathrm{rpm}$ for $4 \mathrm{~min}$. An aliquot of $500 \mu \mathrm{L}$ of the supernatant of each suspension was transferred into a separate test tube to which excess BSA protein was then added ( $36 \mu \mathrm{L}$ of $8 \mathrm{mg} / \mathrm{mL}$ BSA solution), and the unconjugated reagent dye was spectroscopically determined at an excitation wavelength of $595 \mathrm{~nm}$. Absorbance measurements were transformed to BSA protein equivalents $(\mu \mathrm{g} / \mathrm{mL})$ using the standard curve. The amount of protein attached to the nanoparticles was estimated by subtracting the absorbance of the unconjugated reagent from that initially added. Two control determinations were included: the first was prepared by mixing $50 \mathrm{mg}$ of uncoated nanoparticles with $10 \mu \mathrm{L}$ of EDC and $890 \mu \mathrm{L}$ of distilled water; the second contained $50 \mathrm{mg}$ of uncoated nanoparticles in $900 \mu \mathrm{L}$ of distilled water.

2.5. Stability in Physiological Fluid and $p H$ Stability. In order to examine if the BGO nanoparticles could be utilized as biolabel, their photoluminescence was tested in different environments of $\mathrm{pH}$ and human fluids. The photoluminescence was studied by dispersing the particles into human urine, blood serum, and distilled water. One milligram of BGO was mixed into $1.5 \mathrm{~mL}$ of each fluid and dispersed in an ultrasonic bath. The stability of BGO nanoparticles under different $\mathrm{pH}$ conditions was assayed in water. The basal $\mathrm{pH}$ value for water was 5.7. Extreme $\mathrm{pH}$ conditions were explored in water by adding nitric acid and ammonia solutions, to test the stability under acid and alkaline environments, respectively. The $\mathrm{pH}$ of these fluids was then adjusted to test BGO at values of 1 and 12 .

2.6. Functionalization of BGO Nanoparticles with Antibodies. After BGO nanoparticle functionalization with BSA protein either with or without carbodiimide (EDC) as linker (described in Section 2.3), the W6/32 monoclonal antibody 
(mouse IgG2a) that recognizes human HLA I molecules present on nucleated human cells was added at a concentration of $7.5 \mu \mathrm{g}$ per $50 \mathrm{mg}$ of nanoparticles (Table 1). W6/32 $\mathrm{mAb}$ was purified from ascitic fluid following institutional guidelines and provided by Dr. Y. Rosenstein.

Particles were incubated in this solution at $37^{\circ} \mathrm{C}$ for $2 \mathrm{~h}$. Primary antibody-functionalized nanoparticles were washed three times with $100 \mathrm{mM}$ Tris- $\mathrm{HCl}$ buffer $\mathrm{pH}$ 7.4. Particles were centrifuged and the supernatant was recovered to determine the efficiency of $\mathrm{mAb}$ binding to the nanoparticles. Thereafter, the nanoparticles were resuspended in $500 \mu \mathrm{L}$ of FACS solution (PBS pH 7.4, 2\% fetal calf serum, and $0.01 \% \mathrm{NaN}_{3}$ ) and incubated for $30 \mathrm{~min}$ at room temperature with a fluorophore-conjugated secondary antibody goat-anti mouse IgG coupled with Alexa 488 (Invitrogen Co.), which is excited at $488 \mathrm{~nm}$ and emits at $519 \mathrm{~nm}$. After this period, samples were washed with FACS solution and centrifuged at $1200 \mathrm{rpm}(400 \mathrm{~g})$ for $5 \mathrm{~min}$ at room temperature. Subsequently, samples were analyzed via flow cytometry with a FACSCanto II cytometer and the DIVA software (BD Biosciences). Antibody-functionalized nanoparticles with no secondary antibody and nanoparticles without W6/32 but incubated with the secondary antibody only were used as controls. Data were analyzed with the FlowJo flow cytometry analysis software.

2.7. Cellular Recognition (Targeting). To assess the capacity of the antibody-loaded nanoparticles to recognize the cognate antigen (HLA I) of the W6/32 mAb on human cells, the acute monocytic leukemia cell line THP-1 [HLA I ${ }^{+}$: A2, A9; B5] (ATCC TIB-202) was incubated with the particles at 1:20 cell : particle ratio for $2 \mathrm{~h}$ at $37^{\circ} \mathrm{C}$ in $5 \% \mathrm{CO}_{2}$. This $\mathrm{mAb}$ recognizes a public epitope present on all HLA I molecules [14]. Controls included THP-1 cells, mAb-loaded nanoparticles, and THP-1 cells with nonfunctionalized nanoparticles. A488labeled anti-mouse IgG was used as secondary antibody as described for visualization of $\mathrm{mAb}$ binding to the nanoparticles surface. Samples were fixed with $2 \%$ paraformaldehyde prior to epifluorescence and flow cytometry measurements.

\section{Results and Discussions}

3.1. Structural and Luminescence Properties of BGO Nanophosphor. Figure 1(a) shows the XRD pattern with indexed reflections, matching the JCPDS Card number 340416 of $\mathrm{Bi}_{4} \mathrm{Ge}_{3} \mathrm{O}_{12}$ powders. The sample crystallized in the typical body-centered cubic structure of $\mathrm{Bi}_{4} \mathrm{Ge}_{3} \mathrm{O}_{12}$ with a space group $I \overline{4} 3 \mathrm{~d}$. Transmission electron microscopy analysis confirmed the crystal structure and revealed the morphology of the nanocrystals. Figure 1(b) shows representative TEM images of the powders. The inset of Figure 1(b) shows a highresolution (HR) TEM image of the BGO cubic structure observed along the $\left[\begin{array}{lll}-1 & 3 & -3\end{array}\right]$ zone axis. The nanoparticles have a spherical shape and a size distribution of around $12 \mathrm{~nm}$ of average. The image shows the ( $\left.\begin{array}{lll}3 & 2 & 1\end{array}\right)$ and $\left(\begin{array}{lll}3 & 1 & 0\end{array}\right)$ planes with 0.32 and $0.28 \mathrm{~nm}$ of spacing, respectively, and an angle between them of $21.62^{\circ}$. TEM analysis confirmed the results observed by XRD and suggests the presence of a BGO
TABLE 1: Mixed solution used for antibody functionalization of nanoparticles.

\begin{tabular}{lccc}
\hline & NP & NP + BSA & NP + EDC + BSA \\
\hline $\begin{array}{l}\text { Tris-HCl }(10 \mathrm{mM}) \\
\text { pH 5.5 }(\mu \mathrm{L})\end{array}$ & 983 & 923 & 913 \\
EDC $(0.1 \mathrm{M})(\mu \mathrm{L})$ & - & 10 & 10 \\
$\begin{array}{l}\text { W6/32 } \\
(420 \mu \mathrm{g} / \mathrm{mL})(\mu \mathrm{L})\end{array}$ & 17 & 17 & 17 \\
\hline
\end{tabular}

cubic structure. In our previous work, under the same first annealing conditions, two different phases, $\mathrm{Bi}_{4} \mathrm{Ge}_{3} \mathrm{O}_{12}$ and $\beta-\mathrm{Bi}_{2} \mathrm{O}_{3}$, were obtained [15]. This report states that a second annealing processing at $800^{\circ} \mathrm{C}$ for $1 \mathrm{~h}$ was enough to obtain a pure phase of $\mathrm{Bi}_{4} \mathrm{Ge}_{3} \mathrm{O}_{12}$.

The PL excitation and emission spectra are shown in Figure 1(c). The excitation peaks are centered at 250 and $280 \mathrm{~nm}$, near the band gap edge of the BGO [16]. The BGO sample yielded blueish-white luminescence when excited with UV photons, thus presenting a broadband emission in the visible region, where the maximum peak was centered at $485 \mathrm{~nm}$, associated with the ${ }^{3} \mathrm{P}_{1} \rightarrow{ }^{1} \mathrm{~S}_{0}$ of $\mathrm{Bi}^{3+}$ electron transition. Photoluminescence properties of single crystal BGO have been reported [17] and a typical PL spectrum is included for comparison. The emission band of the BGO powder at $485 \mathrm{~nm}$ is similar to the single crystal emission peak. The radioluminescence experiment revealed a single emission peak centered at $500 \mathrm{~nm}$ (Figure 1(d)). For comparison, the RL curve reported for the single crystal BGO under $\mathrm{X}$-ray excitation is also included [17]. In both luminescence experiments, the emission peaks derive from the ${ }^{3} \mathrm{P}_{1} \rightarrow{ }^{1} \mathrm{~S}_{0}$ electron transition in the $\mathrm{Bi}^{3+}$ ions [18].

The two excitation peaks detected by $\mathrm{PL}$ at 250 and $280 \mathrm{~nm}$ are ascribed to ${ }^{1} \mathrm{~S}_{0} \rightarrow{ }^{3} \mathrm{P}_{1}$ and ${ }^{1} \mathrm{~S}_{0} \rightarrow{ }^{1} \mathrm{P}_{1}$, respectively. The ${ }^{3} \mathrm{P}_{0}$ state is the lowest excited state of $\mathrm{Bi}^{3+}$; however, ${ }^{3} \mathrm{P}_{0} \rightarrow{ }^{1} \mathrm{~S}_{0}$ emission is forbidden. Since the ${ }^{3} \mathrm{P}_{0}$ level is situated below the ${ }^{3} \mathrm{P}_{1}$ level, at low temperatures, the ${ }^{3} \mathrm{P}_{0} \rightarrow{ }^{1} \mathrm{~S}_{0}$ transition occurs, while at higher temperatures (room temperature) the practically allowed ${ }^{3} \mathrm{P}_{1} \rightarrow{ }^{1} \mathrm{~S}_{0}$ emission takes over [19]. Hence, the observed emission of $\mathrm{Bi}^{3+}$ originates from the thermal population of the ${ }^{3} \mathrm{P}_{1}$ level and the ${ }^{3} \mathrm{P}_{1} \rightarrow{ }^{1} \mathrm{~S}_{0}$ electronic transitions. Weber and Monchamp [18] estimated the radiative decay rate from the levels ${ }^{3} \mathrm{P}_{1}$ and ${ }^{3} \mathrm{P}_{0}$ integrating the absorption cross section and the Einstein A-B relationship [18]. Decay time for ${ }^{3} \mathrm{P}_{0}$ is longer than that for ${ }^{3} \mathrm{P}_{1}$. If ${ }^{3} \mathrm{P}_{1}$ levels are within a few $K T$ ( $K$ : Boltzman constant and $T$ : temperature) of ${ }^{3} \mathrm{P}_{0}$, lifetime shortening of the latter due to increased radiative decay may be anticipated.

3.2. BGO Nanoparticles after BSA Protein Functionalization. The conjugated protein determination showed a value of $134.9 \pm 62.3 \mu \mathrm{g}$ protein/g BGO. Protein-containing nanoparticles (BGO-EDC-BSA and BGO-BSA) showed blue color due to the protein reagent binding. Control experiments (BGO-EDC and BGO) do not show nonspecific protein 


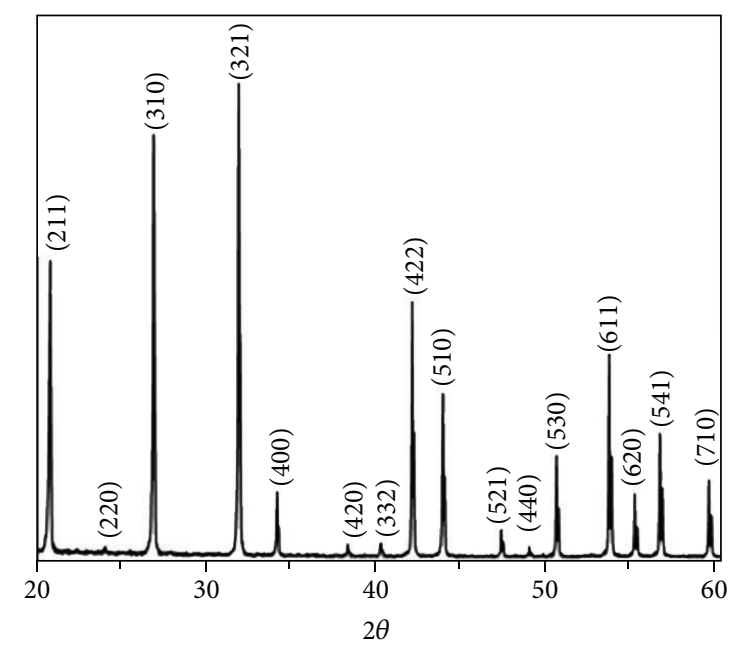

(a)

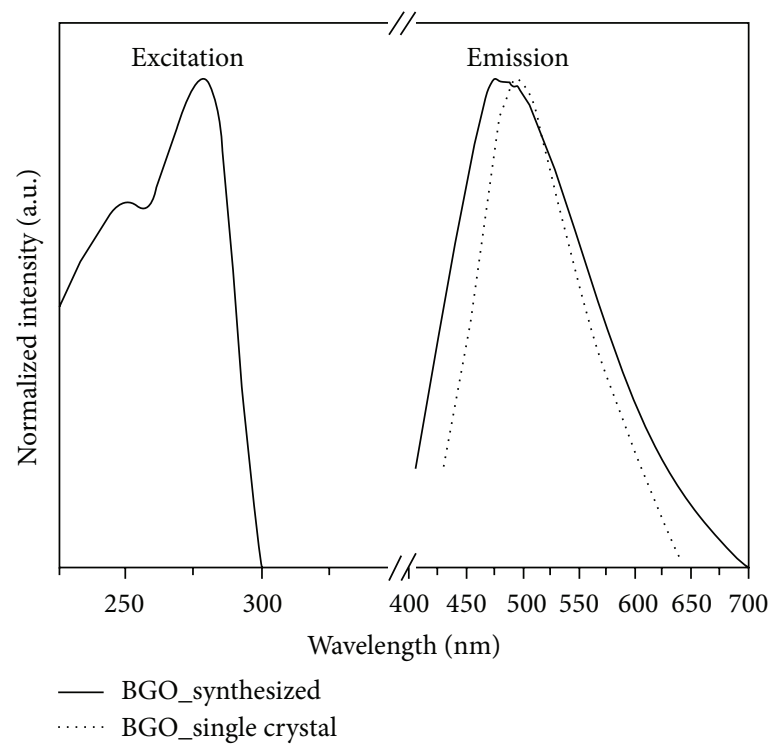

(c)

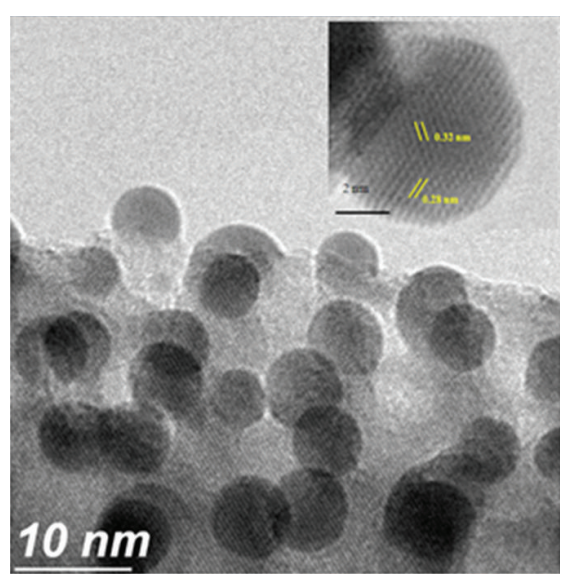

(b)

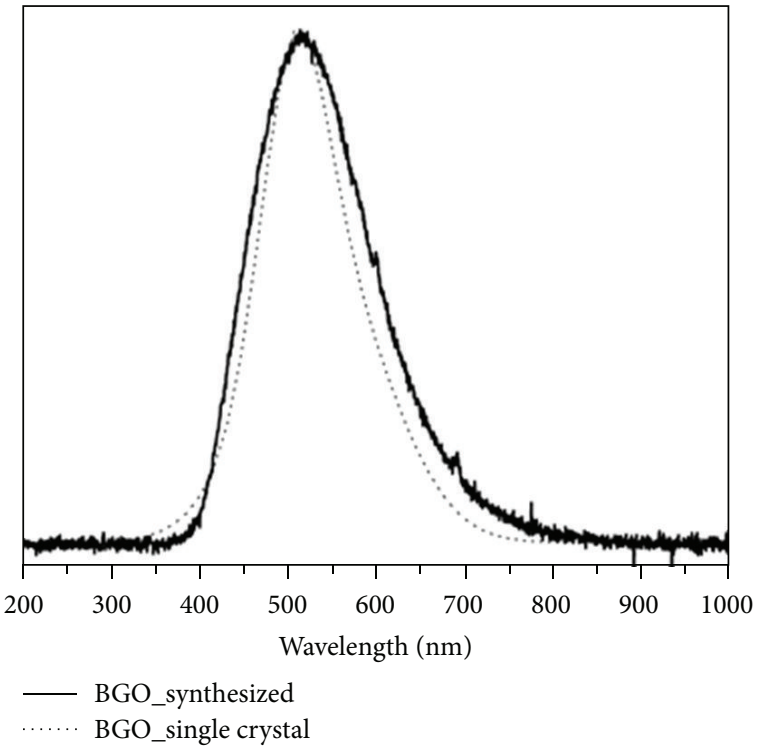

(d)

FIGURE 1: (a) XRD pattern of Bi4Ge3O12. (b) TEM image showing spherical nanocrystalline particles of BGO. (c) PL spectra of BGO; the PL spectrum of the single crystal (dot line) [31] shows similar broadband emission. (d) RL spectra of Bi4Ge3O12 synthesized by sol-gel and annealed by STT. RL spectrum of single crystal BGO (dot line) [31] shows a similar emission band.

reagent adsorption after five washings (Figure 2). The BioRad Protein Assay is a dye-binding assay in which a color change occurs in response to protein concentration. This reagent is an improved preparation of the classical Bradford method [20]. Coomassie blue (dye used for staining proteins) binds to basic and aromatic amino acid residues, especially arginine [21], displaying a color change in response to protein concentration. A color shift from $465 \mathrm{~nm}$ to $595 \mathrm{~nm}$ occurred due to the presence of proteins, suggesting that BSA is contained in the synthesized nanomaterial powder [21]. Figure 3 shows AFM images of the powders with and without BSA. The particles show regular shape and narrow size distribution with an average particle size between 8 and $40 \mathrm{~nm}$ for the uncoated particles and $50-90 \mathrm{~nm}$ for the coated particles. TEM images presented spherical particles, and the size observed by the AFM technique also corresponds to spheres. Thus, the increment in size after functionalization is presumably related to the formation of a protein shell over the BGO particles.

To identify the amino groups that characterize the EDC and BSA organic molecules, infrared and Raman spectroscopy were conducted. The infrared spectrum of uncoated BGO shows intense bands of $\mathrm{Bi}-\mathrm{O}$ and $\mathrm{Ge}-\mathrm{O}$ [2224] moieties in the low wavenumber region, as shown in Figure 4(a). After the BGO functionalization with BSA, the powder showed bands of $\mathrm{O}-\mathrm{H}$ and $\mathrm{N}-\mathrm{H}$ stretching vibrational modes, which reveal the presence of water and amino acid molecules. The wide band around $3300 \mathrm{~cm}^{-1}$ results from hydrogen bonds at different degrees involving water, amino, or hydroxyl groups, thus widening the range of vibrational 


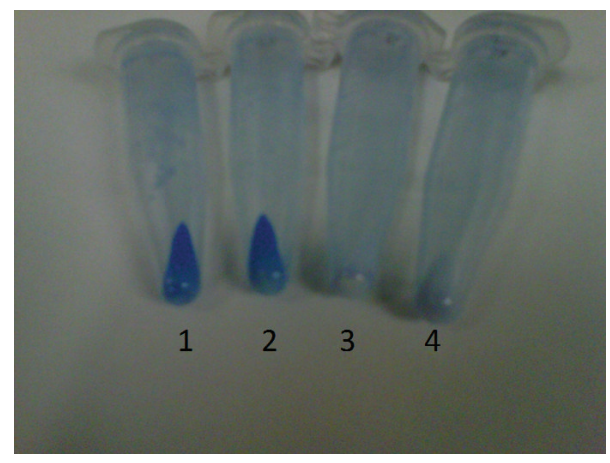

FIGURE 2: BGO nanoparticles preparations after protein reagent treatment and later centrifugation. (1) BGO nanoparticles treated with BSA in the presence of EDC in $10 \mathrm{mM}$ Tris $\mathrm{HCl}$. (2) BGO nanoparticles treated with BSA in the absence of EDC in $10 \mathrm{mM}$ Tris $\mathrm{HCl}$. (3) BGO nanoparticles treated with EDC and without BSA in $10 \mathrm{mM}$ Tris $\mathrm{HCl}$. (4) BGO nanoparticles in $10 \mathrm{mM}$ Tris $\mathrm{HCl}$ without BSA and EDC.

frequencies. The stretching mode of carbonyl of amides groups at $1650 \mathrm{~cm}^{-1}$ [25] clearly confirms the presence of $\mathrm{BSA}$, and no changes were detected in BGO vibrations at 1095 , 857,780 , and $480 \mathrm{~cm}^{-1}$. Thus, the molecular integrity of BGO was maintained in the functionalized BGO particles, which is needed to preserve the light emission properties of BGO.

Raman analyses conducted on BGO particles showed a typical profile (Figure 4(b)) formed by lattice vibrations below $300 \mathrm{~cm}^{-1}$ and $\mathrm{Bi}-\mathrm{O}$ or $\mathrm{Ge}-\mathrm{O}$ fractions up to $730 \mathrm{~cm}^{-1}$, as reported elsewhere [25-27]. A band of low intensity at $530 \mathrm{~cm}^{-1}$ is detected in the spectra of samples treated with EDC, with BSA, and with higher intensity in the EDC-BSA treated sample, which can be assigned to the amino groups of the protein chains, since the amino groups linked to metal centers present a skeletal bending mode between 550 and $250 \mathrm{~cm}^{-1}$ [25]. This signal is further evidence indicating the presence of BSA on the BGO particles. This vibrational mode is confirmed by the shoulder found in the FTIR spectrum of the BGO-EDC-BSA sample near $550 \mathrm{~cm}^{-1}$.

3.3. Photoluminescence Stability of BGO in Human Urine, Blood Serum, and BSA Protein at Different $p H$ Values. In order to prove if BGO powders can function as biolabel, it must firstly corroborate the luminescence of these nanoparticles in different chemical environments such as blood serum, human urine, water, and air. PL spectra were obtained from samples subjected to different organic fluids: human urine $(\mathrm{pH}=7.2)$, blood serum $(\mathrm{pH}=7.28)$, and carbodiimideBSA solution $(\mathrm{pH}=5.5)$, which were compared with the powder dispersed in water $(\mathrm{pH}=5.7)$, as shown in Figure 5(a) under excitation of $280 \mathrm{~nm}$. The emission peak at $485 \mathrm{~nm}$ corresponds to the typical emission attributed to ${ }^{3} \mathrm{P}_{1} \rightarrow{ }^{1} \mathrm{~S}_{0}$ electron transition of $\mathrm{Bi}^{3+}$ ions [27]. The relative intensity of the emission spectrum did not change in the different fluids. However, the small shift in the emission spectrum of the blood serum could be due to the biological molecules which blood serum possesses such as glucose and lipids, absorbing the photons that are emitted in a wavelength region between 400 and $500 \mathrm{~nm}$. The nanoparticles were suspended in the different fluids for two weeks and measured daily (data not shown). In the case of human urine and blood serum, they were maintained half a day because the biological fluids are degraded rapidly at room conditions. The BGO nanoparticles show high optical stability in the different fluids, which make BGO nanoparticles applicable as biolabel.

Figure 5(b) shows the intensity of PL spectra for the nanoparticles dispersed in aqueous solutions at different $\mathrm{pH}$ values (the solutions were maintained and measured for two weeks). A PL spectrum obtained from the nanoparticles in air is also included. The photoluminescence diminished in all dispersed solutions probably due to the light absorption of the media. Besides, under extreme acidic condition $(\mathrm{pH}=$ 5.7 and 1), the PL emission still occurs. This resistance against acid $\mathrm{pH}$ opens the possibility of using the $\mathrm{BGO}$ nanoparticles for biological applications.

On the other hand, urine, blood serum, and cerebrospinal fluid are common fluids for disease diagnosis because they can be easily obtained and contain significant information. For example, the gastrointestinal cancers alter the $\mathrm{pH}$ profile in humans, which initiates extremely acidic in the stomach at $\mathrm{pH}$ of $1-2.5$, then in the small intestine at $\mathrm{pH} 6.6$, and 7.0 in the colon [28]. Thus, the BGO nanoparticles are stable and preserve their luminescence properties in a $\mathrm{pH}$ range of 1 to 12 , which makes these nanoparticles an excellent candidate for biomedical applications as biolabels.

3.4. BGO Functionalization with W6/32 Antibody and Recognition of Leukemia Human Cells. The side scatter (SSC, complexity) versus forward scatter (FSC, size) cytometry plot of nonfunctionalized BGO nanoparticles shows that nanoparticles are distributed along the $10^{4}$ to $10^{5}$ values, confirming their heterogeneity (Figure 6(a)). In order to assess the potential coupling of antibodies to particles that were either functionalized with BSA and carbodiimide or only carbodiimide or left untreated (Table 1), particles were incubated with the W6/32 mAb as specified under Materials and Methods. After removing the excess antibody, particles were further incubated with a fluorophore- (A488-) labeled secondary antibody and the relative fluorescence intensity was measured as compared to particles incubated only with the secondary antibody. As shown in Figure 6(b), independently of the functionalization process, all particles bound equivalent amounts of the W6/32 mAb. Also, independent of the treatment, the nonspecific binding of the secondary antibody to the particles was equivalent and overlapped with the histogram of particles that were left untreated (data not shown).

To further explore whether the binding capacity of the W6/32 mAb to its cognate antigen (HLA I) on the THP1 cell surface was not affected by the carbodiimide (EDC) treatment, cells were incubated with the Ab-coated EDCtreated nanoparticles and particle binding to the cells was assessed with A488-labeled secondary antibody by flow cytometry. Figure 7(a) shows the relative size (FSC) and complexity (SSC) of the BGO nanoparticles (NP, upper 


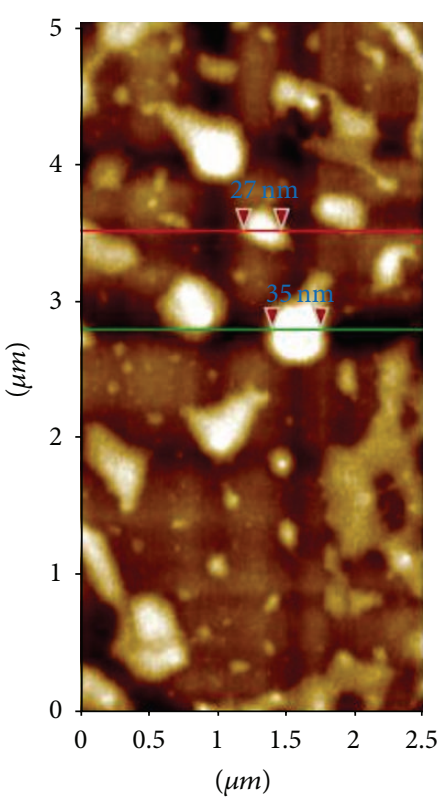

(a)

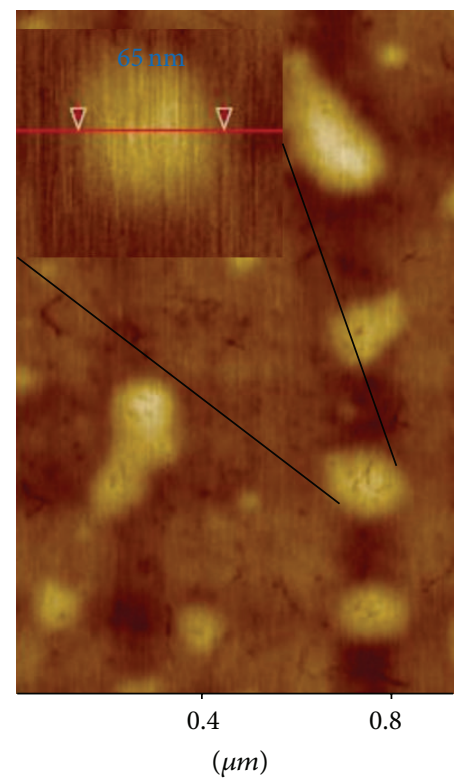

(b)

FIGURE 3: AFM image of BGO nanoparticles. The red and green lines are the AFM section analysis that show nanoparticles size (a) before and (b) after the BSA functionalization. TEM images presented spherical particles, and the size observed by the AFM technique also corresponded to spheres. Thus, the increment in size after functionalization is presumably related to the formation of a protein shell over the BGO particles.

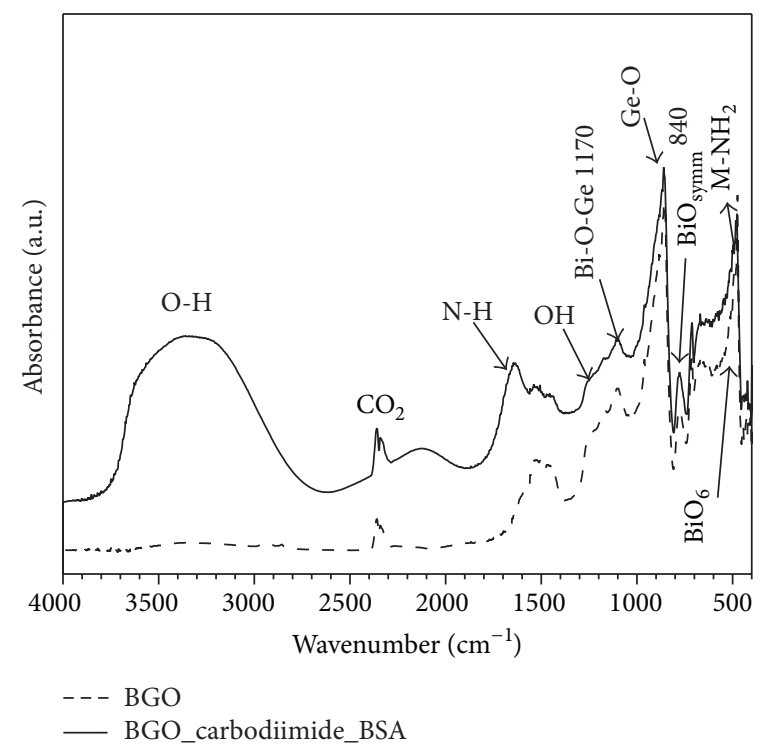

(a)

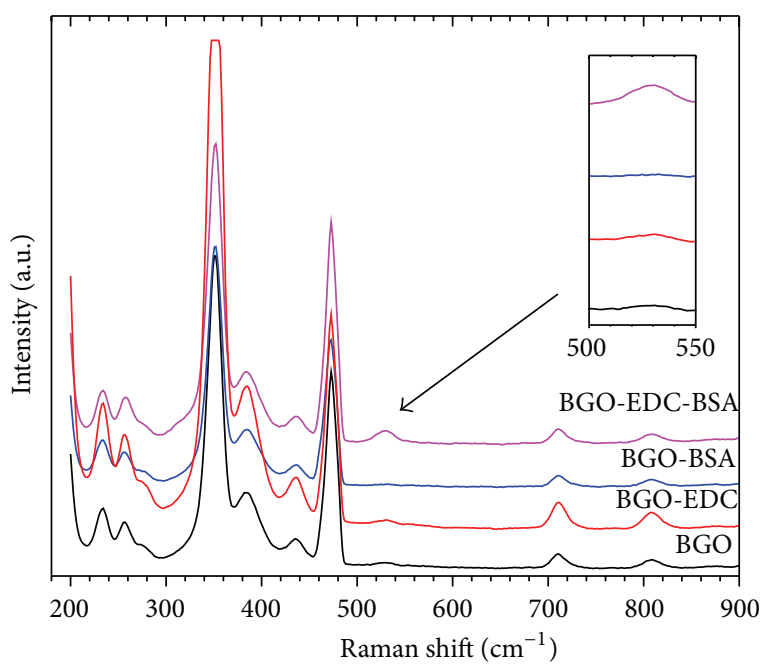

(b)

FIGURE 4: (a) Infrared spectra of BGO nanoparticles before (dashed line) and after (solid line) BSA functionalization. (b) Raman analysis of $\mathrm{BGO}$ at different stages of BSA functionalization.

panel) and those of control THP-1 cells (lower panel) on a linear scale. Incubating the cells with BGO-W6/32 labeled particles and the secondary antibody (blue dot plot) resulted in enhanced complexity/granularity of the cells (upward shift on the SSC axis) as compared to cells incubated with control, particles, not coated with the W6/32 mAb but incubated with the secondary antibody (red plot). The change in complexity/granularity reflects the binding of the antibody-labeled particles to the HLA I molecules on the cell surface (Figure 7(b), upper panel). The presence of the $\mathrm{W} 6 / 32 \mathrm{mAb}$ and hence that of the BGO particles on the cell surface were evaluated by measuring the relative fluorescence intensity of the cells. The shift of the histograms to the right (Figure 7(b), lower panel) indicates that all cells bound 


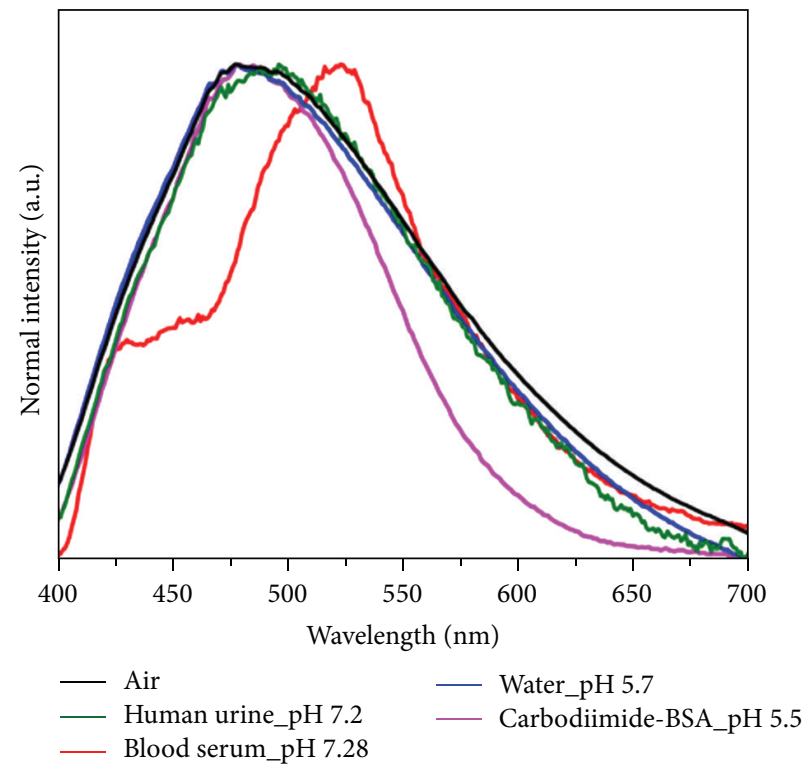

(a)

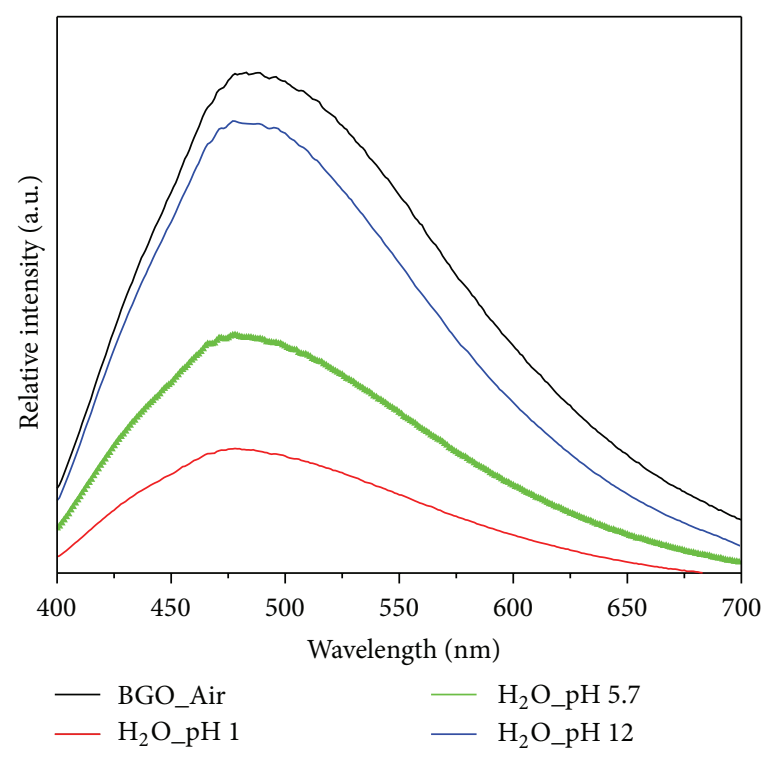

(b)

FIGURE 5: (a) Photoluminescence spectra of the BGO powder in different fluids: human urine (green), blood serum (red), water (blue), BSA protein (pink), and air (black). (b) Emission spectra of BGO dispersed in distilled water with different pH values: $\mathrm{pH} 1$ (red), pH 5.7 (green), and $\mathrm{pH} 12$ (blue). Emission spectrum in air (without fluid) was included for comparison (black). $\lambda_{\mathrm{ex}}=280 \mathrm{~nm}$.

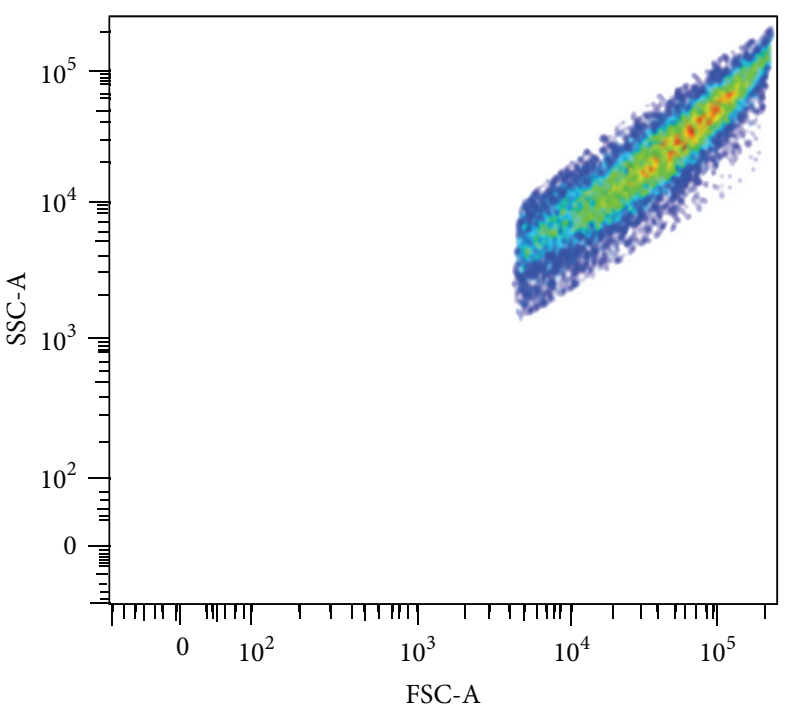

(a)

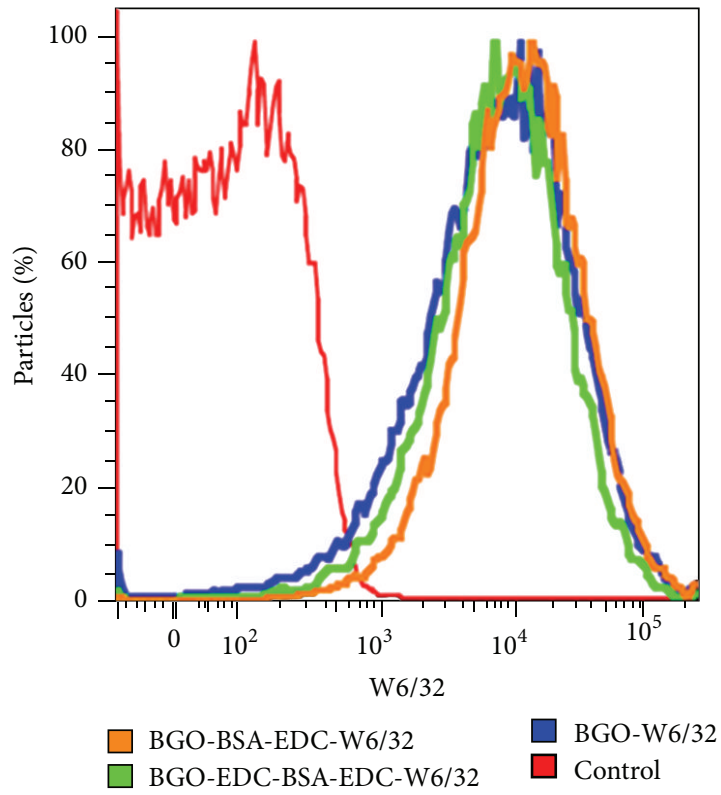

(b)

FIGURE 6: (a) Scattering of nonconjugated BGO nanoparticle. (b) Histograms of W6/32 conjugated BGO nanoparticles subsequently treated with fluorophore-conjugated anti-mouse IgG. A solution of nanoparticles without antibody was added as control.

mAb-labeled nanoparticles, consistent with the increased granularity/complexity of the cells shown in Figure 7(a).

THP-1 cell recognition by the W6/32-functionalized BGO nanoparticles was also assessed by optical microscopy, confirming the association of the BGO nanoparticle with MHC I molecules on the cell surface (Figure 7(c)).
The most important result of this work is that BGO nanoparticles can be functionalized with antibodies, in this case, an anti-MHC I mAb, enabling them to recognize cell surface molecules on tumor cells such as THP-1 cells. This evidences that BGO nanoparticles are suitable as biolabel. In addition to this result, a further benefit emerged from 

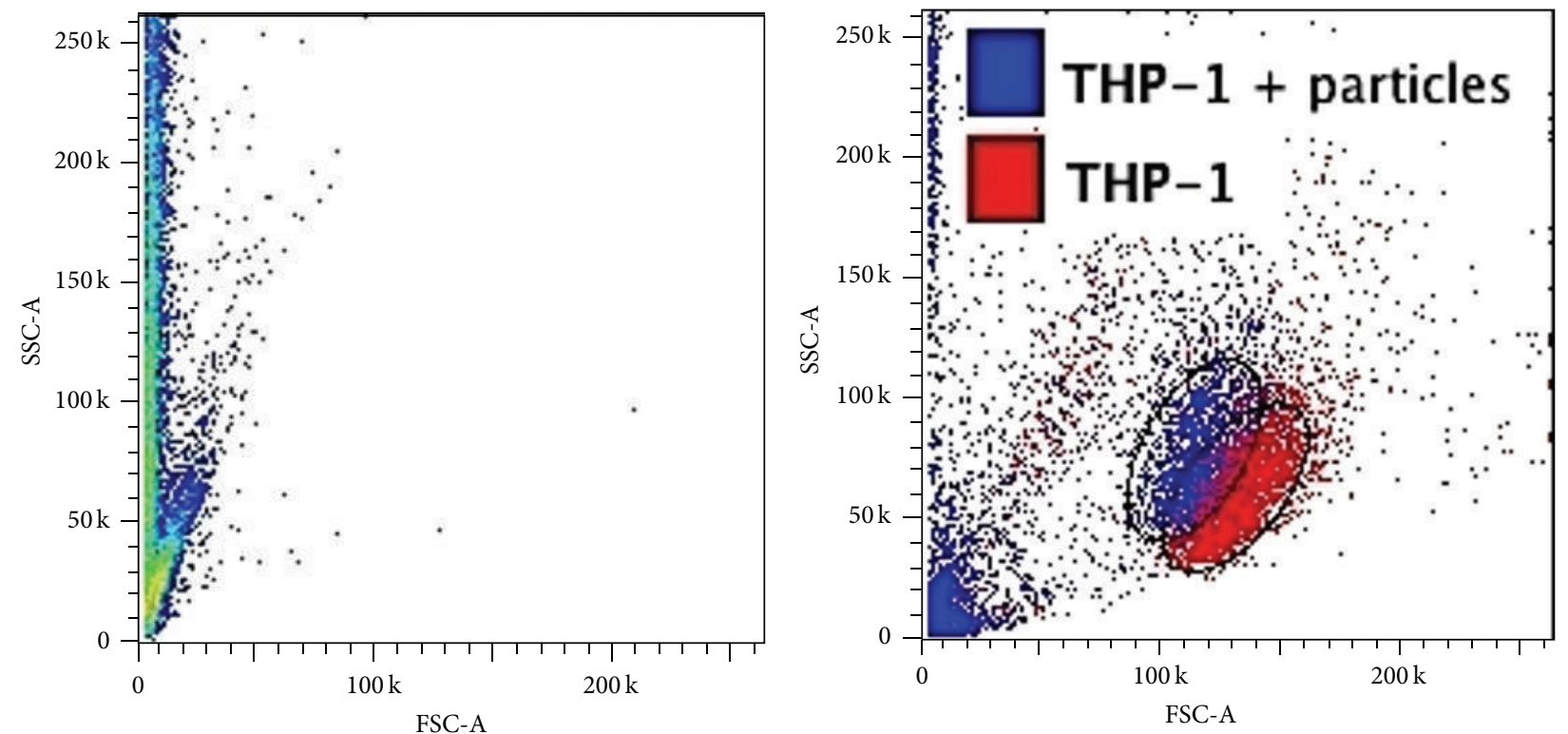

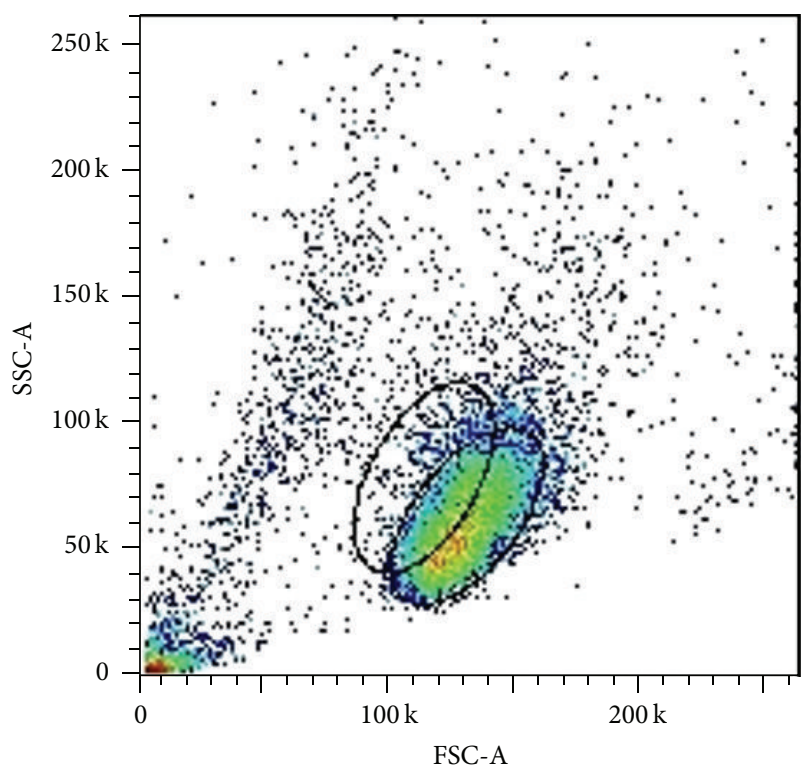

(a)

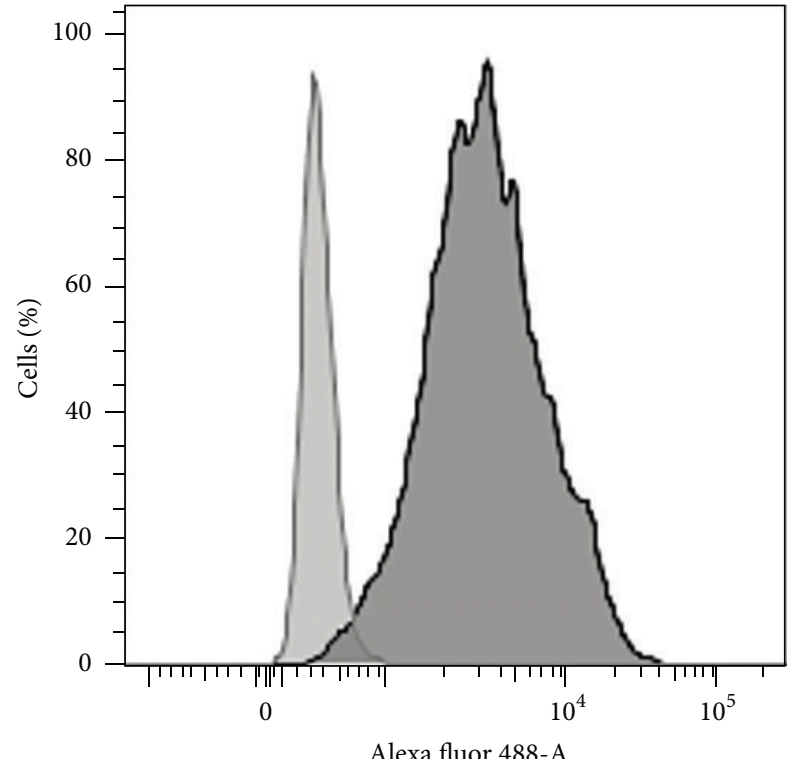

(b)

BGO-EDC-BSA-EDC-W6/32-IgG

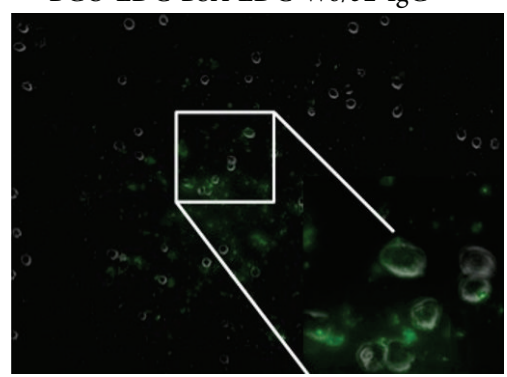

(c)

Figure 7: BGO-W6/32 mAb-labeled nanoparticles recognize HLA I molecules on THP-1 cells. (a) Relative size and complexity of nanoparticles (NP, upper panel) and control THP-1 cells (lower panel) on a linear scale. (b) Complexity of THP-1 cells incubated with mAb-labeled nanoparticles (blue dot plots) or without nanoparticles (red dot plots) upper panel. Fluorescence histogram of the THP-1 cells combined with the W6/32-functionalized nanoparticles (lower panel), incubated with or without Alexa 488 secondary antibody (dark grey and light grey, resp.). (c) Image of fluorescence on the THP-1 cell surface due to BGO nanoparticles functionalized with W6/32 antibody. Objective 60x and ocular 10x, final magnification 600x. 
this study. The quite similar scintillating behavior of BGO nanoparticles compared with the commercial single crystal BGO detectors suggests that BGO nanoparticles could be good components of high-energy detectors. Overall, data reported here (lower oxidative stress as compared with carbon nanotubes and $100 \mu \mathrm{M} \mathrm{H}_{2} \mathrm{O}_{2}$, stability in different biological environments, capacity of $\mathrm{mAb}$-functionalized BGO particles to recognize neoplastic cells antigens, and scintillation properties) support that BGO nanoparticles might be considered as a prospective candidate for further biological applications such as bioimaging to reveal the presence and position of tumors.

\section{Conclusions}

Bismuth germanate $\left(\mathrm{Bi}_{4} \mathrm{Ge}_{3} \mathrm{O}_{12}, \mathrm{BGO}\right)$ nanoparticles were successfully synthesized by the sol-gel method. The nanoparticles yielded strong blueish-white luminescence under UV excitation, showing a single peak at $485 \mathrm{~nm}$ associated with the electronic transitions of the $\mathrm{Bi}^{3+}$. The uncoated and bovine serum albumin-coated nanoparticles presented high optical stability in organic components (human urine, blood serum). They showed photoluminescence properties under different $\mathrm{pH}$ values $(\mathrm{pH}=1$ to $\mathrm{pH}=12)$. In addition, $\mathrm{BGO}$ nanoparticles were successfully functionalized with BSA protein and with W6/32 antibody and they can recognize human acute monocytic leukemia cells. Further investigations are under progress in order to determine the applicability of these nanoparticles to specific cancer cell detection of human neoplasms.

\section{Conflict of Interests}

The authors declare that there is no conflict of interests regarding the publication of this paper.

\section{Acknowledgments}

Technical support was provided by E. Aparicio, F. Ruiz, I. Gradilla, J. A. Peralta, E. Flores, D. Dominguez, J. A. Díaz, Erika Melchy, and M. I. Perez-Montfort. The authors acknowledge the financial support from CONACYT (Grant nos. 100555 and 82984) and DGAPA UNAM (Grants IN109013 and IN-101509). Z. S. Macedo acknowledges the Brazilian Synchrotron Light Laboratory (LNLS), Proposal D04B-XAFS1-9349.

\section{References}

[1] Q. Q. Zhao, A. Boxman, and U. Chowdhry, "Nanotechnology in the chemical industry-opportunities and challenges," Journal of Nanoparticle Research, vol. 5, no. 5-6, pp. 567-572, 2003.

[2] N. Sozer and J. L. Kokini, "Nanotechnology and its applications in the food sector," Trends in Biotechnology, vol. 27, no. 2, pp. 82-89, 2009.

[3] H. Boulaiz, P. J. Alvarez, A. Ramirez et al., "Nanomedicine: application areas and development prospects," International Journal of Molecular Sciences, vol. 12, no. 5, pp. 3303-3321, 2011.
[4] P. Morganti, "Use and potential of nanotechnology in cosmetic dermatology," Clinical, Cosmetic and Investigational Dermatology, vol. 3, pp. 5-13, 2010.

[5] M. Haselman and S. Hauck, "The future of integrated circuits: a survey of nanoelectronics," Proceedings of the IEEE, vol. 98, no. 1, pp. 11-38, 2010.

[6] S.-H. Yeom, B.-H. Kang, K.-J. Kim, and S.-W. Kang, "Nanostructures in biosensor: a review," Frontiers in Bioscience, vol. 16, no. 3, pp. 997-1023, 2011.

[7] A. T. Bell, "The impact of nanoscience on heterogeneous catalysis," Science, vol. 299, no. 5613, pp. 1688-1691, 2003.

[8] D. Knopp, D. Tang, and R. Niessner, "Review: bioanalytical applications of biomolecule-functionalized nanometer-sized doped silica particles," Analytica Chimica Acta, vol. 647, no. 1, pp. 14-30, 2009.

[9] R. De La Rica and H. Matsui, "Applications of peptide and protein-based materials in bionanotechnology," Chemical Society Reviews, vol. 39, no. 9, pp. 3499-3509, 2010.

[10] X. H. Gao, L. Yang, J. A. Petros, F. F. Marshall, J. W. Simons, and S. Nie, "In vivo molecular and cellular imaging with quantum dots," Current Opinion in Biotechnology, vol. 16, no. 1, pp. 63-72, 2005.

[11] E. M. Goldys, K. Drozdowicz-Tomsia, S. Jinjun et al., "Optical characterization of Eu-doped and undoped Gd2O3 nanoparticles synthesized by the hydrogen flame pyrolysis method," Journal of the American Chemical Society, vol. 128, no. 45, pp. 14498-14505, 2006.

[12] J.-H. Park, L. Gu, G. V. Maltzahn, E. Ruoslahti, S. N. Bhatia, and M. J. Sailor, "Biodegradable luminescent porous silicon nanoparticles for in vivo applications," Nature Materials, vol. 8, no. 4, pp. 331-336, 2009.

[13] I. G. Valais, C. M. Michail, S. L. David et al., "Luminescence emission properties of $(\mathrm{Lu}, \mathrm{Y})_{2} \mathrm{SiO}_{5}: \mathrm{Ce}$ (LYSO:Ce) and (Lu, $\mathrm{Y}) \mathrm{AlO}_{3}: \mathrm{Ce}$ (LuYAP:Ce) single crystal scintillators under medical imaging conditions," IEEE Transactions on Nuclear Science, vol. 55, no. 2, pp. 785-789, 2008.

[14] P. Parham, "Use of a monoclonal antibody (W6/32) in structural studies of HLA-A,B,C, antigens," The Journal of Immunology, vol. 123, no. 1, pp. 342-349, 1979.

[15] M. J. Oviedo, O. Contreras, C. E. Rodriguez, Z. S. Macedo, G. A. Hirata, and J. McKittrick, "Photo- and radioluminescence characteristics of bismuth germanate nanoparticles by sol-gel and pressure-assisted combustion synthesis," Optical Materials, vol. 34, no. 7, pp. 1116-1119, 2012.

[16] S. Polosan and M. Secu, "X-ray excited luminescence and photoluminescence of $\mathrm{Bi}_{4}\left(\mathrm{GeO}_{4}\right)_{3}$ glass-ceramics," Radiation Measurements, vol. 45, no. 3-6, pp. 409-411, 2010.

[17] F. A. A. De Jesus, R. S. D. Silva, and Z. S. MacEdo, "Synthesis of $\mathrm{Bi}_{4} \mathrm{Ge}_{3} \mathrm{O}_{12}$ ceramic scintillators by the polymeric precursor method," Journal of Thermal Analysis and Calorimetry, vol. 100, no. 2, pp. 537-541, 2010.

[18] M. J. Weber and R. R. Monchamp, "Luminescence of $\mathrm{Bi}_{4} \mathrm{Ge}_{3} \mathrm{O}_{12}$ : spectral and decay properties," Journal of Applied Physics, vol. 44, pp. 5495-5499, 1973.

[19] O. M. Bordun, "Influence of oxygen vacancies on the luminescence spectra of thin $\mathrm{Bi}_{4} \mathrm{Ge}_{3} \mathrm{O}_{12}$ films," Journal of Applied Spectroscopy, vol. 68, no. 6, pp. 974-978, 2001.

[20] M. M. Bradford, "A rapid and sensitive method for the quantitation of microgram quantities of protein utilizing the principle of protein-dye binding," Analytical Biochemistry, vol. 72, no. 1-2, pp. 248-254, 1976. 
[21] S. J. Compton and C. G. Jones, "Mechanism of dye response and interference in the Bradford protein assay," Analytical Biochemistry, vol. 151, no. 2, pp. 369-374, 1985.

[22] P. Beneventi, R. Capelletti, L. Kovacs, A. Peter, A. M. L. Manotti, and F. Ugozzoli, "FTIR spectroscopy of $\mathrm{OH}$ stretching modes in BSO, BGO and BTO sillenites," Journal of Physics Condensed Matter, vol. 6, no. 31, pp. 6329-6344, 1994.

[23] S. S. Rojas, J. E. De Souza, M. R. B. Andreeta, and A. C. Hernandes, "Influence of ceria addition on thermal properties and local structure of bismuth germanate glasses," Journal of Non-Crystalline Solids, vol. 356, no. 52-54, pp. 2942-2946, 2010.

[24] P. Yu, L. Su, H. Zhao et al., "Spectroscopic properties of $\mathrm{OH}^{-}$ doped and Bi-rich $\mathrm{Bi}_{4} \mathrm{Ge}_{3} \mathrm{O}_{12}$ crystals by vertical Bridgman method," Journal of Luminescence, vol. 131, no. 8, pp. 1608-1611, 2011.

[25] K. Nakamoto, Infrared and Raman Spectra of Inorganic and Coordination Compounds: Applications in Coordination, Organometallic, and Bioinorganic Chemistry. Part 2, Infrared and Raman Spectra of Inorganic and Coordination Compounds, John Wiley \& Sons, Hoboken, NJ, USA, 2009.

[26] J. H. Cho, S. J. Kim, and Y. S. Yang, "Structural change in $\mathrm{Bi}_{4}\left(\mathrm{Si}_{x} \mathrm{Ge}_{12-x}\right)_{3} \mathrm{O}_{12}$ glasses during crystallization," Solid State Communications, vol. 119, pp. 465-470, 2001.

[27] D. F. Evans, G. Pye, R. Bramley, A. G. Clark, T. J. Dyson, and J. D. Hardcastle, "Measurement of gastrointestinal $\mathrm{pH}$ profiles in normal ambulant human subjects," Gut, vol. 29, no. 8, pp. 10351041, 1988.

[28] R. L. Levine, J. A. Williams, E. R. Stadtman, and E. Shacter, "Carbonyl assays for determination of oxidatively modified proteins," Methods in Enzymology, vol. 233, pp. 346-357, 1994. 

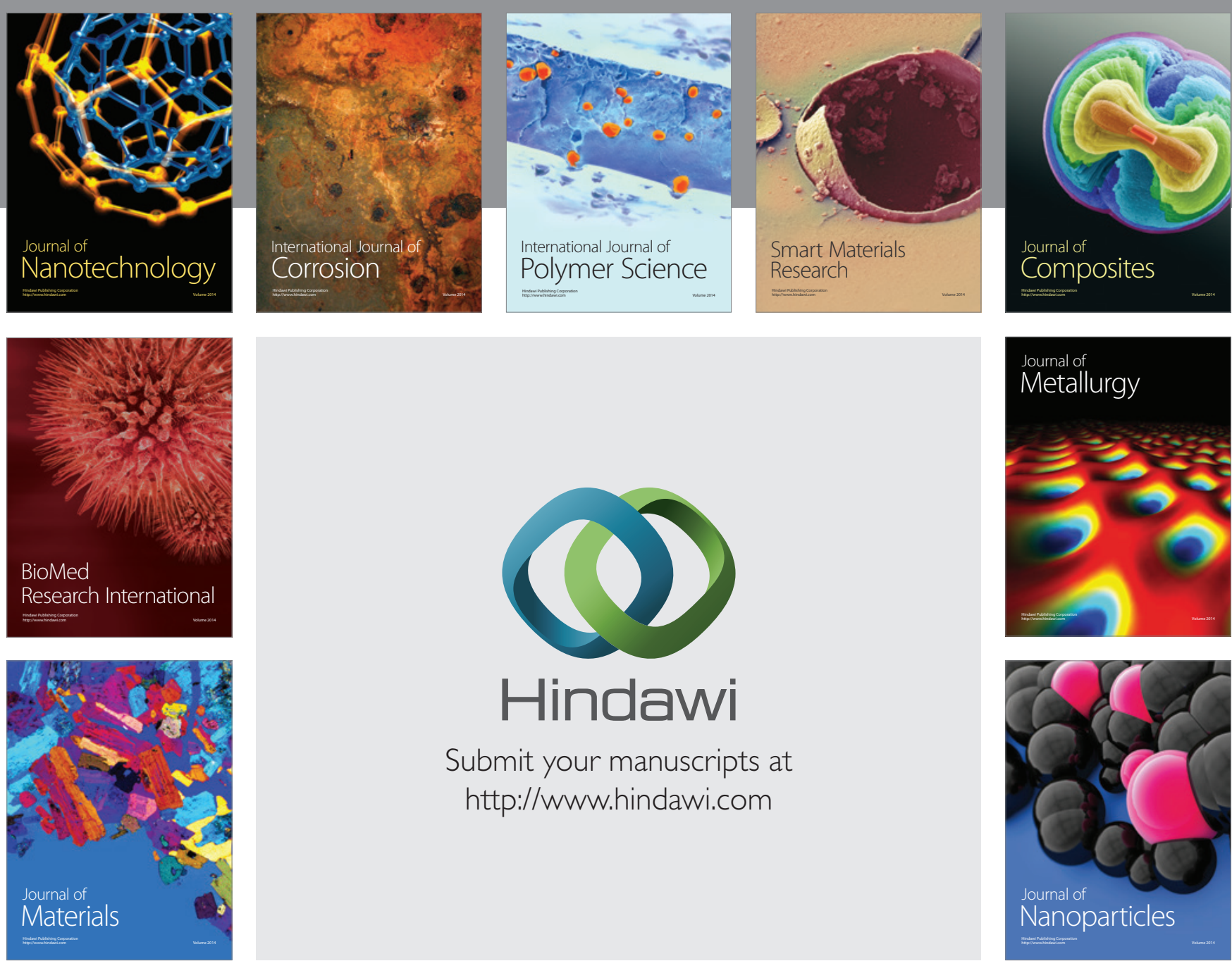

\section{Hindawi}

Submit your manuscripts at

http://www.hindawi.com

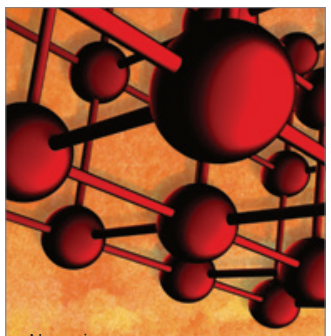

Materials Science and Engineering
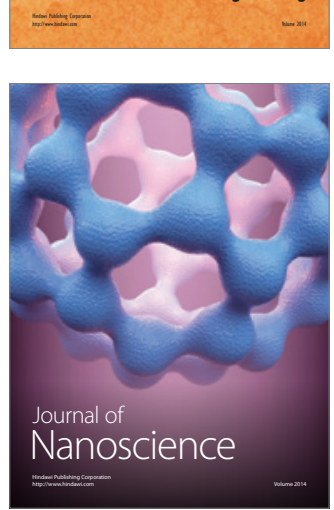
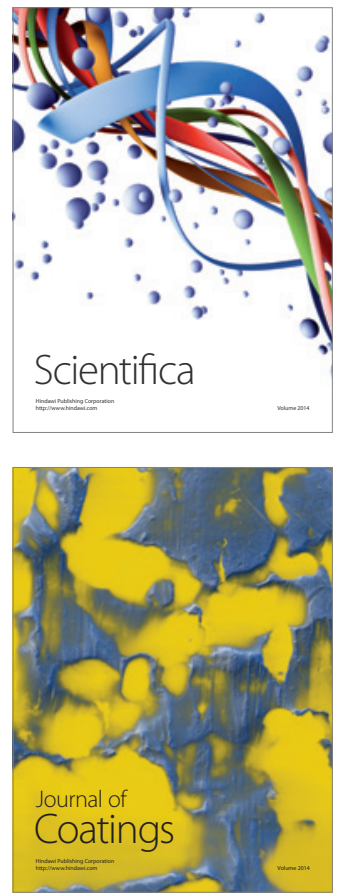
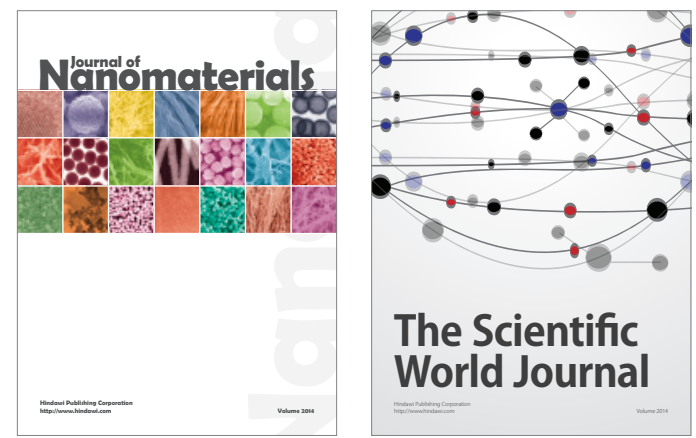

The Scientific World Journal
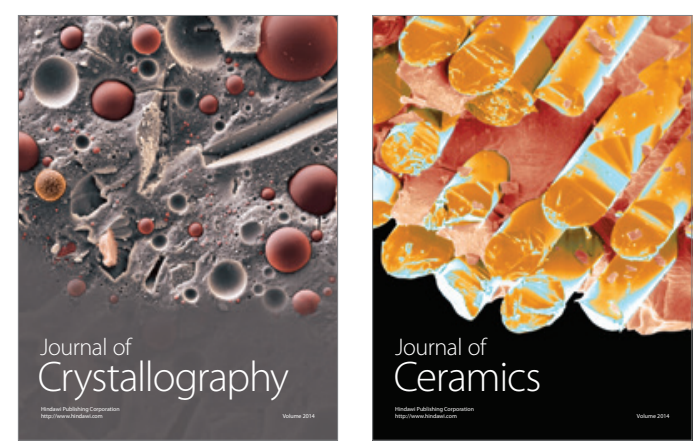
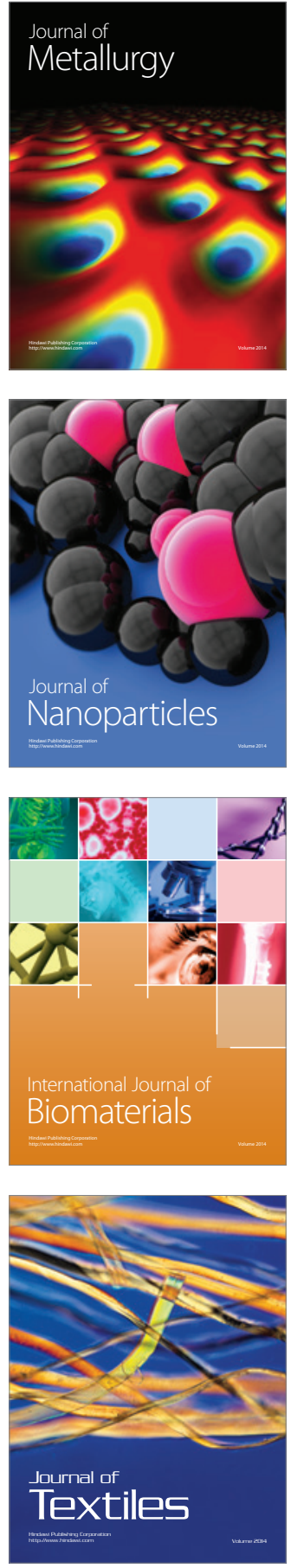